\title{
Varieties of Us: a case study in boundary and landscape in Aotearoa/New Zealand.
}

\section{Paul Woodruffe \& Ian Henderson}

\section{Introduction}

On Auckland's North Shore a narrow strip of cliff-top land overlooking the Hauraki Gulf includes a memorial park, historic WW2 defensive artefacts, Maori fortifications and a section of the New Zealand Walkway, and is edged by both historic public housing and private residences, with a diversity of boundary conditions and internal landscape treatments.

Cadastral boundaries, the markers of surveyed legal ownership of land, are often understood as the determining elements of landscape conditions and treatments, whether intentionally designed or not. These particular edges limit the perception, attribution and design of the continuity of the landscape, and also of other possible boundaries or determinants of difference. This paper explores the signs, symbols and cues of territorial claim, ownership, occupancy, access, use and edge condition, to reveal a richness of landscape beyond the limitations of the duality of public/private based on cadastral lines or of the third space of in-between-ness, often seen as one of difference.

Traditional indigenous Maori land occupation and guardianship may add a potential reinterpretation to this diversity, challenging these cadastral demarcations.

The methodology "the everyday collective laboratory", a graphic story telling of the landscape, is used to explore and illuminate the complex issues of territorial claim and boundary treatment discovered at the site. This is done by using a combination of mapping, fine art methodology, normative landscape architectural site analysis and graphic design to produce a document that is both analysis, and an informing of design potential through "representing the site as fields of relations rather than as arrangements of objects." (Marot, 2003,p2. ). This methodology also enables memory to become a material and a dimension for landscape architecture within the suburban condition through its ability to draw out narrative.

\section{Surveying the boundary: colonial obsession in NZ}

Landscape boundaries have played a potent, persistent and defining role in Aotearoa/New Zealand society since the early days of colonization, and continue to do so.

Ideas of landscape perform a role in the colonizing process in a pragmatic way, converting the landscape to reflect those ideas, to suit the colonizing powers and establish ownership (Byrnes, 2000). Early colonists arrived in NZ in the mid nineteenth century with certain culturally defined expectations of the landscape, a landscape presumed to be empty, without the marks of civilized society, in need even of 'salvation from a state of wilderness' as Byrnes describes it. To be able to set about the necessary "improvements" to this landscape, the first requirement was surveying. Note the film Illustrious Energy, dir. Leon Narby (1988), the narrative of the film played out against a distant background activity of surveying, ubiquitous and at the same time apparently innocuous. In nineteenth century NZ, an apparent lack of a landscape organized for both cultural and economic purposes was replaced with a landscape of rigid and prescribed demarcations.

In parallel with the enormous, pressing and thorough task of surveying, was an industrious group of landscape painters. Their paintings tended to reveal a gentle sylvan idyll, often empty of people or evidence of settlement, but full of potential (for European rural productive enterprises). A number of paintings (e.g. The town and part of the harbour of Nelson in 1842, about a year after its first 
foundation, John Saxton, 1845: Illustration 1) even proudly foreground the surveyor, his activities and the surveyed landscape.

\section{(Illustration1)}

Out of an unbounded and undifferentiated landscape was forged a colonized landscape of divisions, containment and difference. It was also a landscape that excluded the indigenous people.

From a Maori perspective the land was occupied and the landscape was neither undifferentiated nor unbounded, though these were all expressed in ways different from and 'unreadable' to the surveying colonists. Ahi ka, keeping the home fires burning, or in other words maintaining settlement presence, was the primary claim to a site, supported by a complex system of guardianship or husbandry, kaitiaki. Maori as a people, their social and political organisations of tribes and sub-tribes,iwi and hapu, and these forms of occupation played little or no part in the new colonizing surveys, except where they obstructed its path.

The practice of surveying and establishing rigid legal demarcations everywhere reconstructed the landscape in accordance with European expectations of personal, social and productive space. This delineated landscape set aside public and private space, reflecting the colonizing organization of personal and social space.

\section{Public and private}

Walzer called public space as that shared with strangers: "its character expresses and also conditions our public life, civic culture, everyday discourse" (1986, as cited in Woolley, 2003, p. 3). Woolley defines private space as individual gardens and homes, a description somewhat short of the capacity for individual and creative difference that the character of private space assumes, and the individual use and activity that private space permits. If indeed public space expresses and conditions our public (external) life, the internal life of domesticity (home and garden) expresses personal culture, individuality and intimate discourse.

Divisions between public and private therefore express a difference of type of space. This may be expressed as bounded space, territorial claim, or of difference in treatment, and often all three. Access to public landscapes, to that space shared with strangers, is generally open and unhindered; access to private landscapes on the other hand is restricted, by barrier or social convention, often reinforced by physical cues. Because of the individuality of private space, and its consequent treatment, differences also occur of course between one domestic circumstance and the next.

In New Zealand these expressions of distinction of and between private and public, and of the demarcation of the boundary, perhaps due to the newness of the surveyed landscape, and of the territorial claims over this landscape, have been highly valued, within of course a landscape that fits the cultural expectation.

However, is the clarity of survey, boundary and difference as obvious as our history and enthusiasm for boundaries would suggest? Or are various landscape conditions, particularly those pertaining to edge, a lot less precise, and open to individual interpretation?

One example, that many in $\mathrm{NZ}$ are familiar with, demonstrates some challenge to the rigidity of the legal demarcation. In coastal places, especially within small rural communities, boundaries are often created or dissolved for social or practical reason. Often fluid, often with little attention given to surveyed boundaries, with less distinction between public and private, recognition of these is occasionally agreed upon verbally, sometimes understood and adhered to by convention, or reinforced by activity. This different sort of boundary recognition may accommodate beach access, limited space 
for boat storage or the playing of team ball sports in the summer, or even the delivery of a fish for breakfast.

As this particular example demonstrates, within the extent of the landscape, concepts of inside and outside, of public and private, and of the conditions that distinguish these, are more likely to be indeterminate and ambiguous than fixed and prescribed. As de Sola-Morales claims: "Periphery as a project is to propose an idea which does not necessarily coincide with the geographical field of the existing periphery" (2008, p3.).

The resultant spaces of NZ's colonizing project may have only the appearance of unity or even homogeneity; that in reality they constitute a multiplicity of fragmented spaces (Byrnes, 2000). Allen has suggested that while a landscape might have a level of commonality, what he calls "field condition", it is nevertheless constituted of a variety of elements:

Field configurations are loosely bounded aggregates characterized by porosity and local interconnectivity. The internal regulations of the parts are decisive; overall shape and extent are highly fluid. Field conditions are bottom-up phenomena

Allen, 1997, p.

De Sola-Morales (2008) allows that it is the voids or instertices that might have power or be considered positive material, not just the fragmented parts or the aggregates themselves.

\section{A technique to reveal}

A technique, developed by one of the authors, Paul Woodruffe, involving painting, drawing and social memory, explores particular landscapes through artistic representation, drawing on a variety of disciplines, fostering collaboration between them. Such a technique can engage from bottom up by being in the landscape, and be open to interpretations of both variety and specificity, through artistic expression. As Leavy has observed "Visual art challenges viewers in an immediate and visceral way while remaining open to a multiplicity of meanings" (2009, p68.). This use of fine art methodology together with exhibition and publication design, can have the kind of benefits also observed by Leavy:

"The turn toward artistic forms of representation brings social research to broader audiences, mitigating some of the educational and social biases that have traditionally dictated the beneficiaries of academic scholarship."

Leavy, 2009.

In his book How to look at painting Justin Paton (2005) named one chapter "How to be looked at by a painting". Like art, landscape is an active participant in our experience of it. Hunt (2004) has described a garden as haptic, even palpable. We could extend this to include other landscapes as well, given that our experience of them is similarly haptic and both close at hand and interior (within and of the landscape). Ross (1998) has asserted that an invitation lies within this physicality, an invite that we respond to, not only through our bodies and senses, but also by exercising our imagination. So the appreciation of landscapes is integral with experience of it, even within it, not able to be had from afar. Kemp (1998, as cited in Holly, 2002) also described the appreciation of works of art dependent on the information inherently possessed by that object. So too, landscapes hold information, the kind that we can stub our toe on, envelops us in intimate spaces, or that triggers memory or even imagination.

\section{the everyday collective laboratory}

This technique, the everyday collective laboratory, is exercised close at hand. It has the immediacy of close observation, but also of being there within. Subjective experience informs the artwork. This 
experience is both immediate, engaging with what is at hand now, but also recalling past experiences of the site, even childhood ones. The artwork therefore is a representation of both the haptic and visceral qualities of a landscape but also a record of social memory. Myriad clues, often of fragments, of that landscape are embedded in the experience and in the art. As such it has the capacity to offer an interpretation of qualitative distinctiveness of a site. The painting style also purposely echoes Allen's (1997) loosely bounded aggregates and local interconnectivity to give effect to the site's heterogeneity (rather than homogeneity) of spatial organization.

At this site (case study below), the everyday collective laboratory, employing close observation, memory and artistic representation, reveals evidence of ways of expressing boundary, occupancy and possession. The technique reveals landscape conditions that may have a variety of boundary conditions (apparent or not) and a range of relationships of adjacent spaces one with another, including that of private to public.

\section{Case study: Kennedy Park/NZ Walkway/Rahopara Pa}

The chosen site is on Auckland's North Shore. It is composed of a narrow strip of cliff-top land overlooking the Hauraki Gulf with a memorial park, J.F. Kennedy Park, historic WW2 defensive artefacts, a $p a$ (historical fortified Maori position) site, Rahopara Pa, and a section of the NZ Walkway (Te Araroa). It is also edged in a variety of ways by both historic public housing and private residences.

\section{(Illustration2)}

The whole site, as described above, is shown in Illustration 2. The image describes the journey backwards and forwards across the site and memories of the site from another era. These are captured as slices across the site to demonstrate relationships, and as moments depicting fragments of artefacts, which invest character in the landscape. Historical activities, especially seafood gathering by Maori along the foreshore, are also depicted, emerging as an enriching layer from the artist's memory.

Property lines are submerged beneath cross-site bands of related landscape fields and connections, combining residential gardens and houses with park, cliff and sea. The painting demonstrates both the site's connections and the fragmentation of its elements. Cadastral indicators, such as rock wall, wire fence, park barrier and letter box, while clearly present, are in pieces, marginal, and sometimes almost ephemeral. Together they do not disturb the continuity of the landscape, and only partially declare public/private transitions. The most pronounced sense of edge is that of the cliff, a topographical feature that is the clearest physical boundary on site, between land and sea, cliff top and sea level, with a ring of large pohutukawa trees (Metrosiderosexcelsa), and marking different activities, experiences, and memories. This graphic description prefaces the various parts explored in the following paintings.

The research concentrates on four examples found at the site where park boundary meets residential housing, and examines how these work in terms of public/private experience and social history. Different parts of the site have produced distinct names to emphasise the particularity of differing boundary treatments and/or occupancy cues above and beyond the simplistic category of public or private. The different characteristics identified in the four examples have been named: inconsistent, explicit, implied, and assimilated. These illustrated categorizations of edge and boundary condition are the result of observation and experience within and particular to the site.

\section{(Illustration3)}

\section{Inconsistent. The old State House: Illustration 3}


The artwork reveals several key elements that suggest occupation as well as conditions that suggest the site might be unoccupied and that ownership is in question. The latter proved on closer inspection to be stronger: the elements that suggest occupation are either archaic, degraded or at complete odds with the surrounding occupied housing; the site has few implied and no explicit landscape features that reinforce a sense of occupation, such that the visitor might feel as though trespassing or unwelcome. This site was found to have a permeable edge, so that it is almost assimilated into the surrounding park landscape. This is due to planting type and minimal maintenance evident in the garden. Inconsistencies encountered such as the washing line and letterbox prevented a complete assimilation however. Visual cues on approach tend to discourage entry, and these cues may have been successful in preventing any unwanted occupation or vandalism. The ambiguous sense of public openness and private occupation seems to reflect mid $20^{\text {th }}$ century State tenanting. The State residential style minimised boundary barriers, a style supported by a strong sense of community. The unmodified site still imparts a sense of this era, with its archaic architecture and landscape.

\section{(Illustration4)}

\section{Explicit. The new house: Illustration 4}

An approach to this site from any one of the three sides that border the park provides a similar boundary condition. The soft and fluid landscape elements that surround the site give way to a concretised boundary, the demarcation explicit. The impenetrable boundary seems fortress-like, safely containing domestic privacy. The design of the boundary appears to reflect a contemporary desire for security and privacy, and a prevailing sense of ambivalence towards neighbours. When contrasted with the old state house, it reflects differences in the use and effects of boundary design between mid $20^{\text {th }}$ century and sixty years on. Due to its isolation from other housing developments, and its close proximity to the old state house and open space, this boundary is visually at odds with the surrounding landscape.

\section{(Illustration5)}

\section{Implied. A house on the New Zealand Walkway:Illustration 5}

A sense of presence is employed to great effect in the third site to imply use and occupation. A method of strategic artefact placement, using objects easily associated with personal space, declares occupation, but in a quiet way. Reinforcing the occupation is stated by the use of two chairs rather than a single one. Objects placed at or near what might be assumed to be the property edge link to the domestic chairs on the veranda, connecting the intimate space of house with the outer reaches of the property. In addition, two large pohutukawa trees (Metrosiderosexcelsa) just outside the legal boundary of the property act as a perceived common natural barrier between public and private. This combination of factors, both contrived and possibly accidental, has enabled the site to appear more expansive than the legal survey. This site has a boundary that is implied through a shared cultural understanding of artefacts that reflect use and occupation. Its symbolism is consistent determining a message of occupation (unlike the State house). The strategy that this site employs to effect edge and boundary is one commonly found at baches, cribs and beach houses throughout coastal New Zealand, built and occupied by communities that engaged in shared social events such as barbeques and beach cricket, the success of social interaction relying on shared private landscapes. This site has the New Zealand Walkway immediately in front of it.

\section{(Illustration6)}

\section{Assimilated. A pa site house: Illustration 6}

This site is closely connected to the land in both visual and topographical terms, sitting within what was the main defensive trench for theRahopara Pa site. Obviously the surveyed lines cut through the former $p a$ site, with no regard to its prior occupants, claimants or use, or to its archaeological value, parts of it having been occupied by Maori sporadically for several hundred years. The house sits in the entrenched fold of the land, which provide natural boundaries on both sides, the building height being 
below the $p a$ site and Walkway entrance. The scale, colour method of construction, and placement below and within significant landscape features permit it to be well assimilated with its surroundings. The fence height and glass panels enable the visitor to briefly experience the private world of the occupier and in turn be observed. This in itself is effective in discouraging people from doing anything other than passing quickly through the trench going to or from the pa site. In a similar manner to the open trench the site/house acts as a landscape feature monitoring entry and exit to the $p a$ site, and acting in a way that seems neither public nor private, but perhaps a little of each. This type of property edge design is commonly found in sites that were built during the 1960's, 70's and 80 's, where a careful mix of separation and integration of private and public space can be observed.

This image also reveals apparent Maori artefacts in the palisading and carvings, signalling Rahopara $\mathrm{Pa}$ as a Maori site, but divested of any singular identity. Maori carvings are most often personified: more than a representation, they are the ancestor whose face is carved. These carvings are in the form of a head, but faceless. So the acknowledgement is distinctly token, the ownership claim kept firmly within the public realm, by the local council.

All the residential housing that borders the park and the walkway can be categorized within varying degrees into these types. It was observed that the period of construction played a large part in which boundary and edge category they belonged to, the newer the construction the more explicit and less subtle the demarcation of private and public became. The four examples shown give a brief history in the way residential edge and boundary in this area have been designed over the last seven decades, and to some extent how the sense of community has varied within that time. Experience within the site discovered that explicit boundaries were no more likely to show occupation than the assimilated and implied ones, and those properties completely isolated from the surrounding parkland by explicit boundary had greatly diminished influence on their adjacent landscape in terms of activity and fauna.

\section{Conclusion}

This project, utilizing what the authors call the everyday collective laboratory, has pointed to the strength in landscape characteristics often overlooked in traditional site analysis methods and not apparent in existing available geophysical data. The project succeeded in offering a systematic methodology of undertaking site analysis using painting and drawing, while supported by GIS and publication design.

It also contributed to the discourse on boundary and edge as urban condition in a way that offers an alternative to the purely geotechnical and sociological data collection methods used in site analysis, and helps to establish the site as the regulatory idea of the project. Both the continuity of the landscape across boundaries, physical, legal, fixed by convention, or imagined, and the fragmentation of that landscape into parts, disconnected by space, object, difference, memory or time, are made evident on this particular site by this technique. It reveals what de Sola-Morales calls the force of the peripheral place "in the void between disconnected objects" (2008, p2. )

Painting has a role to question the nature of defining site conditions, including boundary, by becoming "a tool to explore, read, reveal, invent and ultimately represent" (Marot, 2003, p2. ), in this case representing and therefore revealing varieties and permutations of boundary. So this visual representation technique presents a challenge to the existing expectations of boundaries, possession or occupancy, rather than legitimising these as painting once did in nineteenth century NZ. Much of what was revealed in this exploration could only have been discovered by means of painting and drawing.

"Theresultantcognitiveshiftenablespreconceptionsaboutlandscapestobedownplayed,andwaysofanalyzi nglandscapestobeenhanced." (Griffiths, 2005).

While it has generally been assumed that the surveyed boundary conditions determine edge, there are 
many variations to the realisation or demonstration of occupation, ownership or possession, including differences between internal and external landscape conditions, cues of external activity or occupation, gestures of gardening, or privacy or of domesticity.

This study of a landscape through painting and drawing, in response to experiencing the internal, haptic nature of landscapes and in recall of memory, makes evident different layers to landscape conditions and the specificity of characteristics of particular sites, expanding and enhancing the analysis of landscapes. Consequently it has demonstrated the capacity to reach beyond the traditional public/private divide and ideas of edge common to our post-colonial landscape framework, providing a more subtle, ambiguous and potential hybrid of spaces.

Paul Woodruffe

Lecturer

Department of Design

UNITEC New Zealand

Pwoodruffe@unitec.ac.nz

Private Bag 92025, Auckland, NZ

Ian Henderson

Lecturer

Programme Leader

Department of Landscape Architecture

Unitec New Zealand

ihenderson@unitec.ac.nz

Private Bag 92025, Auckland, NZ

\section{References}

Allen, S. (1997). From Object to Field. In Architectural Design: Architecture after geometry, 67/ 5,6. London: Academy Editions.

Byrnes, G. (2000). Surveying space: constructing the colonial landscape. In B. Dalley\& B. Labrum (Eds.), Fragments: New Zealand social and cultural history. Auckland, New Zealand: Auckland University Press.

De Sola-Morales, M. (2008).A matter of things.Belgium: NAi Publishers.

Griffiths, C. (2005). Reframing the Given.Unpublished mater's thesis, Unitec New Zealand, Auckland, New Zealand.

Holly, M. (2002). Reciprocity and reception theory. In P. Smith (Ed.), A companion to art theory. Oxford: Blackwell Publishing.

Hunt, J. (2004). The afterlife of gardens. London: Reaktion Books.

Leavy, P. (2009). Method meets Art: arts-based research practice. New York: The Guilford Press.

Marot, S. (2003).Sub-urbanism and the art of memory.London: AA Publishers. 
Hampson, C. \& Reynolds, D. (Producers), \&Narby, L. (Director). (1988). Illustrious Energy [Motion picture]. New Zealand: Mirage Entertainment Corporation \& New Zealand Film Commission.

Paton, J. (2005). How to look at painting. Wellington: Awa Press.

Ross, S. (1998). What gardens mean. Chicago: University of Chicago Press.

Saxton, J. (2000). The town and part of the harbour of Nelson in 1842, about a year after its first foundation. In W. McAloon (Ed.), The Promised Land: art in Nelson from Tasman to today (p. 29). Nelson, New Zealand: The Suter Te Aratoi o Whakatu.

Woolley, H. (2003). Urban Open Spaces. London: Spon Press. 